\title{
Ecological Restoration of Degraded Peatlands in Indonesia: Achieving the UN Sustainable Development Goals
}

\author{
Dr. Charles CC Lee \\ The University of Newcastle, Singapore
}

Extensive peatland areas in Southeast Asia have been degraded through both natural and anthropogenic factors, such as wildfires and deforestation, resulting in severe environmental as well as socio-economic impacts on a local and global scale. Peatland forests, are unique wetland ecosystems where partially decomposed organic matter accumulates over thousands of years under waterlogged conditions to form carbon- rich soils, or peat. They are critical for preserving global diversity, provide safe drinking water, minimise flood risk and help address climate change. In addition, peatlands are the largest natural terrestrial carbon store; the area covered by near natural peatland worldwide ( $>3$ million $\mathrm{km}^{2}$ ) sequesters 0.37 gigatonnes of carbon dioxide $\mathrm{CO}_{2}$ ) a year - storing more carbon than all other vegetation types. Damaged peatlands are a major source of greenhouse gas emissions, annually releasing almost $6 \%$ of global anthropogenic $\mathrm{CO}_{2}$ emissions. Peatland restoration is therefore crucial in emissions reductions, thereby mitigating climate change impacts. The recent "Intergovernmental Science Policy Platform on Biodiversity and Ecosystem Services (IPBES) report shows that land (including peatlands) degradation and restoration negatively impacts at least two-fifths of humanity, and that is both the driver for biodiversity loss and responsible for intensifying climate change and its impacts, contributing to mass human migration and increased conflict." In fact, a recent 2019 UN Environment Programme report details the crucial impact of land restoration and rehabilitation on all 15 Sustainable Development Goals (SDG). This paper will focus on linking peatlands restoration with achieving the SDGs, such as SDG 15, "Life on Land" and SDG 13, "Climate Action". Additionally, a case study on peatlands restoration will be presented in the Sungai Tohor Area in Riau province, Indonesia. The case study will include: (a) a background of the rich peatlands destruction (logging for timber, forest fires, land subsidence and flooding); (b) community and science-based approach to restoration; and (c) current revegetation efforts. 